\title{
Heritability of Anthropometric Phenotypes in Caste Populations of Visakhapatnam, India
}

\author{
RECTOR ARYA, ${ }^{1}$ RAVINDRANATH DUGGIRALA, ${ }^{2}$ ANTHONY G. COMUZZIE, ${ }^{2}$ SOBHA \\ PUPPALA,${ }^{3}$ SAILEELA MODEM, ${ }^{4}$ BHASKARA R. BUSI, ${ }^{5}$ AND MICHAEL H. CRAWFORD ${ }^{6}$
}

\begin{abstract}
In this study, we used anthropometric data from six Andhra caste populations to examine heritability patterns of 23 anthropometric phenotypes (linear, craniofacial, and soft tissue measures) with special reference to caste differences. We obtained anthropometric data from 342 nuclear families from Brahmin, Reddy, Telaga, Nagara, Ag. Kshatriya, and Mala castes of Visakhapatnam, India. These caste groups represent the existing hierarchical stratification of Indian populations. We used a variance components approach to determine the heritability $\left(h^{2}\right)$ of these 23 anthropometric phenotypes (height, weight, BMI, etc.). The sample consisted of 1918 individuals ranging in age from 6 to 72 years $($ mean $=21.5$, S.D. $=13.8)$. The heritabilities $\left(h^{2} \pm\right.$ S.E. $)$ for all anthropometric traits for the entire sample were significant $(p<0.0001)$ and varied from $0.25 \pm 0.05$ (BMI) to $0.61 \pm 0.05$ (bizygomatic breadth) after accounting for sex, age, and caste effects. Since data on socioeconomic and nutritional covariates were available for a subset of families, we repeated the genetic analyses using this subset, which has yielded higher heritabilities ranging from $0.21 \pm 0.16$ (head breadth) to $0.72 \pm$ 0.18 (nasal breadth). In general, craniofacial measurements exhibited higher $h^{2}$ compared to linear measures. Breadth measurements and circumferences yielded more or less similar heritabilities. Age and sex effects were significant $(p<0.0001)$ for most of the traits, while the effects of caste, socioeconomic status, and nutritional status were inconsistent across the traits. In conclusion, anthropometric phenotypes examined in this study are under appreciable additive genetic influences.
\end{abstract}

Anthropometric phenotypes have been used to study the genetic structure of human populations (Relethford and Lees 1982; Blangero 1990; Chakraborthy 1990;

\footnotetext{
${ }^{1}$ Division of Clinical Epidemiology, Department of Medicine, University of Texas Health Science Center, San Antonio, TX 78229.

${ }^{2}$ Department of Genetics, Southwest Foundation for Biomedical Research, San Antonio, TX 78245.

${ }^{3}$ Department of Epidemiology and Biostatistics, Case Western Reserve University, Cleveland, Ohio 44109.

${ }^{4}$ Department of Home Science, St. Joseph's College for Women, Visakhapatnam, India.

${ }^{5}$ Department of Anthropology, Andhra University, Visakhapatnam, India.

${ }^{6}$ Department of Anthropology, University of Kansas, Lawrence, KS 66045.
}

Human Biology, June 2002, v. 74, no. 3, pp. 325-344.

Copyright (? 2002 Wayne State University Press, Detroit, Michigan 48201-1309

KEY WORDS: HERITABILITY, ANTHROPOMETRIC PHENOTYPES, ANDHRA CASTES, VARIANCE COMPONENTS 


\section{6 / ARYA ET AL.}

Duggirala and Crawford 1994). Anthropometric phenotypes are influenced by genetic and environmental factors, in turn exhibiting continuous phenotypic distributions (Falconer 1989). Besides the genetic influences, these phenotypes have been shown to be affected by factors such as sex, birth order, birth weight, and by environmental factors such as nutrition, disease, intrauterine environment, socioeconomic status, and secular trends (Mueller and Titcomb 1977; Eveleth 1986; Kumar and Jain 1988; Tanner 1990; Malik and Singh 1991). As such, anthropometric phenotypes exhibit enormous within- and among-group variation. Numerous studies, using twin and family data, have demonstrated that the variation in anthropometric traits such as height and weight is under the effects of both genetic and environmental factors (Susanne 1977; Byard et al. 1984, 1985a, 1985b; Devor et al. 1986a, 1986b, Sharma and Susanne 1991).

India's unique caste system has attracted the attention of human geneticists and anthropologists to examine the intricacies involved in biological and sociocultural aspects. Morphological diversity among Indian populations is appreciable, since castes differ from each other phenotypically in varying degrees due to differences in their genetic make-up as well as differences in nutritional and socioeconomic factors (Malhotra 1978; Singh 1993). Furthermore, genetic diversity is comparatively high within a given caste group, while the intercaste genetic differentiation is small (Char et al. 1989). This diversity is largely attributable to the effects of evolutionary forces, particularly genetic admixture, through successive historic migrations (Balakrishan 1987; Sharma and Talukder 1987). Thus, India has a great potential for the study of quantitative genetic variation within and between populations, and it offers a unique opportunity to examine the genetic determinants of anthropometric phenotypes of caste groups and to understand the morphologic and/or genetic diversity among caste populations.

Anthropometric variability (i.e., differences in the size and shape of individuals of different ages) in Indian populations is remarkable due to the influences of several factors, such as nutritional and socioeconomic factors (Eveleth 1986; Harrison and Schmitt 1989; Eveleth and Tanner 1990). For example, the effects of malnutrition in children below 14 years of age, who constitute about $40 \%$ of the Indian population, are more serious and lasting, in turn contributing to the remarkable morphological variation (Busi et al. 1991; Reddy et al. 1992). Anthropometric patterns are likely to manifest considerable regional variations in a country like India because of the influence of a variety of factors such as socioeconomic and nutritional status, diet, education, culture, ethnicity, and genetics (Eveleth 1986; Sharma and Talukder 1987; Majumder et al. 1990).

Although some attempts have been made to examine the structure of the caste populations using anthropometric data (e.g., Reddy 1998), knowledge about the genetic basis of anthropometric traits in Indian populations is limited (Kaur and Singh 1981; Sharma et al. 1984; Poosha et al. 1984; Byard et al. 1984; Byard et al. 1985a, 1985b; Sharma 1987). Therefore, in this study we used a variance component approach to examine the genetic architecture of anthropometric phenotypes in Andhra caste populations using nuclear family data. The objectives of 
the present study are: (1) to study the heritability patterns of linear, craniofacial, and soft tissue measures among caste groups; (2) to evaluate the effects of various covariates of these phenotypes using subset data with information on nutritional and socioeconomic status; and (3) to examine the caste-specific heritability patterns with special reference to caste differences.

\section{Materials and Methods}

Study Populations. In this study, we used anthropometric data collected as part of a major study entitled "Nutrition and Growth of Certain Population Groups of Visakhapatnam" (NAG Project, D.O.En.) from 342 nuclear families belonging to Brahmin, Reddy, Telaga, Nagara, Akshatriya, and Mala castes. As shown in Table 1, these six caste populations of Visakhapatnam, Andhra Pradesh, India (Figure 1), represent the three predominant strata (i.e., varna) of the Hindu

Table 1. Hierarchical Classification of Andhra Castes (Varnas) Showing the Study Caste Groups (in Boldface)

Caste (Varna)

\begin{tabular}{lcc}
\hline Upper $^{a}$ & Middle (Sudra) & Lower (Panchama) \\
\hline Brahmin (Br) & Reddy (Rd) & Mala (Ma) \\
& Telaga (Tg) & \\
& Nagara (Ng) & \\
& Agnikula Kshatriya/Akshatriya (Ak) & \\
\hline
\end{tabular}

a. Upper caste and varna carry the same name.

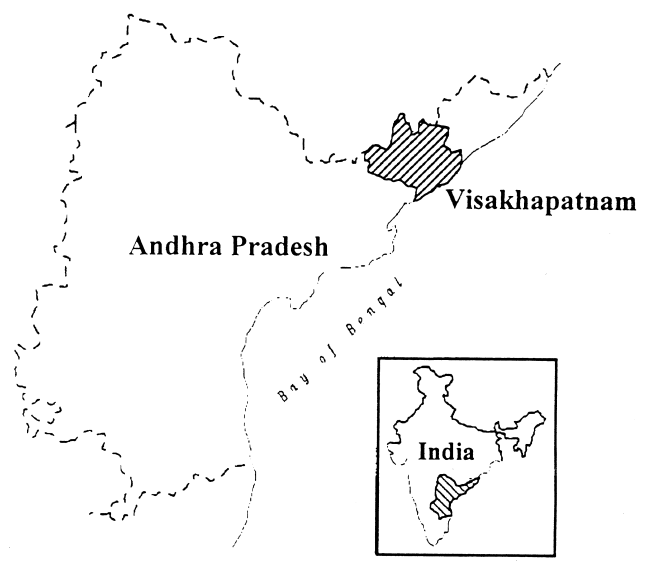

Figure 1. Map of Andhra Pradesh, India, showing the study area, Visakhapatnam. 
caste system, which is hierarchically arranged, from top to bottom, into five varnas: Brahmin (priests and teachers), Kshatriya (rulers and warriors), Vysyas (merchants and traders), Sudras (occupational groups), and Panchama (lower caste groups, which are presently called the scheduled castes) (Lamb 1975; Malhotra 1984). Although the first three varnas are also referred to as castes, the last two varnas (i.e., Sudra and Panchama) have been categorized into a number of primarily occupationally based caste groups. To date, about 3000 castes and subcastes have been identified among the Indian populations (Lamb 1975; Malhotra 1984; Singh 1993). Among the study caste groups, the Brahmins are at the top of the hierarchy, while the Reddy, Telaga, Nagara, and Akshatriya belong to the intermediate caste group (Sudra), and the Mala belong to the lowest (Panchama) (Table 1). Generally, families within these castes in the present study can be classified further into the upper, middle, and lower socioeconomic classes.

Families were selected through simple random sampling techniques. The distribution of the family sample by age, sex, relation, and caste along with sample sizes used in the genetic analysis is presented in Table 2. The sample consisted of 1918 individuals (males $=988$, females $=930$ ) ranging in age from 6 to 72 years. The mean ages of males and females were almost equal. Children above 6 years of age were considered in this study. Age range varied from 6 to 35 years for sons and 6 to 28 years for daughters, though their mean ages were almost equal. As shown in Table 2, the proportion of children $(55.4 \%)$ is slightly higher than that of the adult sample $(44.6 \%)$, whereas the proportions of males $(51.5 \%)$ and females (48.5\%) are more or less similar. The Brahmin caste has the highest mean age with smaller sample size followed by the Mala caste with largest sam-

Table 2. Descriptive Statistics for Age of Subjects by Sex, Relation, and Caste

\begin{tabular}{lccc} 
& Sample Size & Mean \pm S.D. & $\begin{array}{c}\text { Age Range } \\
\text { (Years) }\end{array}$ \\
\hline $\begin{array}{l}\text { Sex } \\
\text { Male }\end{array}$ & 988 & $21.7 \pm 15.3$ & $6-72$ \\
$\quad$ Female & 930 & $21.3 \pm 12.1$ & $6-62$ \\
Relation & & & \\
Father & 390 & $38.6 \pm 10.0$ & $20-72$ \\
Mother & 466 & $31.6 \pm 8.0$ & $17-62$ \\
Son & 598 & $10.7 \pm 4.1$ & $6-35$ \\
Daughter & 464 & $10.8 \pm 3.9$ & $6-28$ \\
Caste & & & \\
Brahmin & 177 & $25.5 \pm 14.3$ & $6-62$ \\
Reddy & 204 & $21.0 \pm 12.5$ & $6-51$ \\
Telaga & 475 & $16.9 \pm 11.2$ & $6-60$ \\
Nagara & 218 & $19.6 \pm 15.3$ & $6-65$ \\
Akshatriya & 232 & $21.4 \pm 14.1$ & $6-64$ \\
Mala & 612 & $24.8 \pm 14.1$ & $6-72$ \\
\hline
\end{tabular}


ple size. Reddy, Akshatriya, and Nagara castes show similar mean ages, while Telaga has the lowest mean age.

Anthropometric Measurements. Twenty-one anthropometric measurements (head and body), as shown in Table 3, were taken on each individual in a family using standard anthropometric techniques (Singh and Bhasin 1968; Weiner and Lourie 1981). Two variables, body mass index (weight in $\mathrm{kg} / \mathrm{height}$ in meters squared) and sum of skinfolds (triceps + subscapular skinfolds), were derived from other variables. Since accuracy of both technique and equipment was important in collecting anthropometric data, the investigators were trained and the measurement techniques were standardized until they attained an accuracy that produced the same values for repeated measures. For example, the accuracy expected was $0.2 \mathrm{~cm}$ in height, $0.1 \mathrm{~kg}$ in weight, $0.2 \mathrm{~mm}$ in fat fold, and $0.2 \mathrm{~cm}$ in arm circumference, when the investigator measured the subject twice at the same time. All measurements were taken on the left side of the individual. In order to minimize the interobserver error, one (male) investigator (R.A.) measured only male subjects while the other (female) investigator (S.P.) measured only female subjects. This data-collection strategy is also necessary in societies such as India, where opposite-sex contact is generally not allowed. For example, Mueller and Titcomb (1977), Poosha et al. (1984), and Byard et al. (1985a, 1985b) have used a similar method of data collection.

Socioeconomic and Nutritional Variables. Socioeconomic (e.g., occupation, per capita income, and education) and nutritional information was obtained in order to assess the environmental component using standard procedures. Socioeconomic and nutritional variables were used as covariates of the anthropometric traits in the genetic analyses. However, nutritional information was available only for a subset of the families. To account for the caste differences, five dummy variables were created in comparison to the reference caste (Mala). Mala caste (ma) was selected as a reference caste because of its large sample size and its position as the lowermost caste in the caste hierarchy. Thus, age, sex, and five dummy variables [i.e. Brahmin (br), Reddy (rd), Telaga (tg), Nagara (ng), and Akshatriya (ak)] were used as covariates.

Nutritional data pertaining to energy, protein, vitamin A, thiamin, riboflavin, niacin, vitamin $\mathrm{C}$, iron, and calcium were collected by a nutritionist (S.M.) using 24-hour recall and weighed intake methods to assess individual dietary intake to ascertain the nutritional status of caste groups (Jelliffe and Jelliffe 1989; Dwyer 1991). Individual nutrient intake was calculated to obtain more precise measurements of average nutrient intake of groups for comparisons with other similar groups, and, in turn, to determine whether there were dietary inadequacies in the study group. The 24-hour intake is fairly easy to obtain by the recall method, and it is informative because individuals cannot accurately recall food intake beyond 24 hours (Jelliffe and Jelliffe 1989; Dwyer 1991). Personnel with relatively little technical background using a standard form and instruction can 
record intake information in a 15- or 20-minute interview. The investigator who conducted the 24-hour recall method interviews used various sizes of glasses, spoons, bowls, or food models to help the subject indicate quantities more accurately. However, dietary intake information obtained through retrospective methods is subject to errors due to recall.

The family dietary intakes were obtained by the interview method. The data on cooked quantities of foods were converted to raw quantities by using the standardized amounts. From the raw quantities of food consumption of each individual, the nutritive value of the diet was calculated using food composition tables (Gopalan et al. 1987). The per capita consumption was estimated from the family's diet by the use of consumption coefficients (Gopalan et al. 1987). Food composition tables based on analysis of foods made at the National Institute of Nutrition, Hyderabad, were used to calculate individual food consumption values. Additional data pertaining to demographic and socioeconomic factors were also collected simultaneously through an oral questionnaire method.

Statistical Analyses. We calculated means and standard deviations, coefficients of variation, and conducted a $t$ test using the statistical software Minitab (Minitab 1994). Coefficients of variation were computed for each of the 23 anthropometric measurements for combined data as well as for males and females separately (Sokal and Rohlf 1981). A test of equality of variances following Sokal and Rohlf (1981) was conducted to determine if two coefficients of variation were significantly different at the $p=0.05$ level in a two-tailed comparison.

Quantitative Genetic Analysis. The total phenotypic variance of a given trait can be partitioned into genetic and environmental components. The proportion of phenotypic variance in a trait that is attributable to additive genetic factors is referred to as heritability $\left(h^{2}\right)$ of the trait (Falconer 1989). Heritability can be estimated from the components of variance using the genetic information contained in the pedigrees (Hopper and Mathews 1982; Lange and Boehnke 1983). In a simple variance component model, variances or covariances between relatives as a function of their genetic relationships can be specified (Hopper and Mathews 1982). For such a simple model, the covariance matrix $(\Omega)$ for a nuclear family is given by

$\Omega=2 \Phi \sigma_{g}^{2}+I \sigma_{e}^{2}$,

where $\Phi=$ kinship matrix; $\sigma_{g}^{2}=$ the variance due to additive genetic effects, $I=$ the identity matrix, and $\sigma_{e}^{2}=$ the variance attributable to the individual-specific random environmental effects.

We estimated heritability along with phenotypic mean, standard deviation, and covariate effects (e.g., age and sex terms) for each phenotype using maximum likelihood techniques (Amos 1994; Almasy and Blangero 1998).

Hypothesis Testing. The significance of the heritability $\left(h^{2}\right)$ of a given phenotype was tested using the likelihood ratio test. The hypothesis of no heritability 
$\left(h^{2}=0\right)$ for a given phenotype was tested by comparing the likelihood of a restricted model in which the parameter $h^{2}$ was constrained to a value of 0 against the likelihood for the general model in which the same parameter was estimated. Twice the difference between the log-likelihood values of these models yields a test statistic $(\lambda)$ that is asymptotically distributed as a $1 / 2: 1 / 2$ mixture of a chisquare distribution with 1 degree of freedom and a point mass at 0 (Hopper and Mathews 1982; Self and Liang 1987). A significant test $(p \leq 0.05)$ is considered as the evidence for a statistically significant, nonzero heritability. The null hypothesis of no influence of a given covariate $(\beta$ covariate $=0)$ was also tested using the likelihood ratio test, which involves comparison for a given parameter and has 1 degree of freedom. Given the nature of data structures and analyses used in this study, a $p$ value of $<0.10$ (i.e., suggestive evidence against the null hypothesis) was used for inclusion of covariates, which may help reduce the problem of a type II error. After evaluating the significance of various parameter estimates, heritability of a given trait was estimated together with its phenotypic mean, standard deviation, and the effects resulting from the selected covariates simultaneously using a final model. The computer program SOLAR was used to perform the quantitative genetic analyses of the anthropometric phenotypes (Almasy and Blangero 1998).

\section{Results}

Descriptive statistics, including raw data means and standard deviations for each of the 23 anthropometric traits of the combined data set, are presented in Table 3. Though every subject was measured for every trait, sample sizes vary across the traits. Values that fall above 3 and 4 (if the distribution was continuous) standard deviations from the mean of a given trait were excluded from the analysis. Means and standard deviations for males and females showed considerable sex differences. As shown in Table 3, HT, SHT, HIS, ARL, BAD, TRC, HL, HB, FHT, NB, WB, BCF, and WT means were slightly higher in males than females. Females showed higher mean values for APC, BCD, ARC, TRS, SSS, BMI, and SSK than males. Also, coefficients of variation were significantly large $(p<0.05)$ for most of the traits, thus indicating more pronounced anthropometric variability. Thus, comparison of means and coefficients of variation between males and females indicated significant sexual dimorphism $(p<0.05)$ for most of the traits. In the combined data set, soft tissue measures appear to be more variable, while linear measures exhibit moderate variability. Craniofacial measures are the least variable with an exception of nasal height and nasal breadth that exhibit moderate variability.

Table 4 shows means and standard deviations for the subset of anthropometric (both sexes combined), including nutritional, variables. As shown in Table 4 , anthropometric variables showed less variation compared to nutritional variables. Anthropometric variables ST, SHT, ARL, BAD, HL, HB, FHT, NH, BZB, 


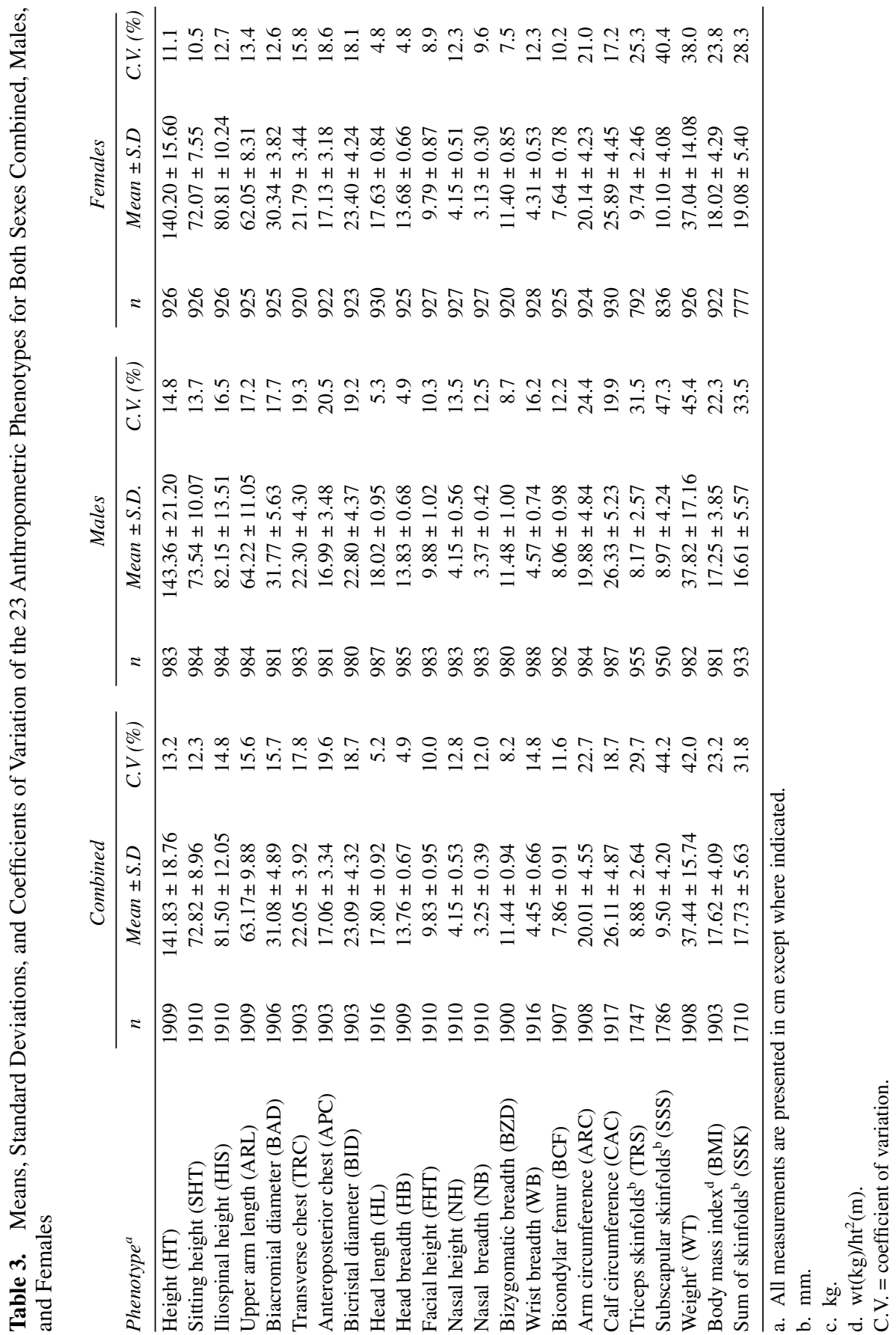


Table 4. Means, Standard Deviations, and Coefficients of Variation of Anthropometric and Nutritional Variables (Subset Data)

\begin{tabular}{|c|c|c|c|}
\hline Variable $^{a}$ & $n$ & Mean \pm S.D. & C.V. $(\%)$ \\
\hline Height & 374 & $151.42 \pm 10.19$ & 6.7 \\
\hline Sitting height & 375 & $77.41 \pm 5.26$ & 6.8 \\
\hline Iliospinal height & 375 & $87.16 \pm 12.05$ & 13.8 \\
\hline Upper arm length & 373 & $67.59 \pm 6.16$ & 9.1 \\
\hline Biacromial diameter & 375 & $33.27 \pm 3.09$ & 9.3 \\
\hline Transverse chest & 373 & $24.15 \pm 2.86$ & 11.9 \\
\hline Anteroposterior chest & 371 & $18.84 \pm 2.51$ & 13.3 \\
\hline Bicristal diameter & 374 & $25.49 \pm 3.05$ & 11.9 \\
\hline Head length & 376 & $18.13 \pm 0.80$ & 4.4 \\
\hline Head breadth & 372 & $13.94 \pm 0.53$ & 3.8 \\
\hline Facial height & 375 & $10.25 \pm 0.64$ & 6.2 \\
\hline Nasal height & 375 & $4.35 \pm 0.41$ & 9.4 \\
\hline Nasal breadth & 375 & $3.31 \pm 0.36$ & 10.9 \\
\hline Bizygomatic breadth & 368 & $11.79 \pm 0.78$ & 6.6 \\
\hline Wrist breadth & 376 & $4.76 \pm 0.44$ & 9.3 \\
\hline Bicondylar femur & 374 & $8.19 \pm 0.67$ & 8.2 \\
\hline Arm circumference & 372 & $22.47 \pm 3.57$ & 15.9 \\
\hline Calf circumference & 375 & $28.65 \pm 3.82$ & 13.3 \\
\hline Triceps skinfolds ${ }^{\mathrm{b}}$ & 312 & $9.34 \pm 3.08$ & 33.0 \\
\hline Subscapular skinfolds & 333 & $11.18 \pm 4.30$ & 38.9 \\
\hline Weight $^{\mathrm{c}}$ & 375 & $45.26 \pm 11.96$ & 26.5 \\
\hline Body mass index ${ }^{d}$ & 373 & $19.48 \pm 3.86$ & 19.8 \\
\hline Sum of skinfolds & 304 & $19.83 \pm 6.22$ & 31.4 \\
\hline Calories (kcal) & 376 & $1455.3 \pm 429.9$ & 29.6 \\
\hline Protein (gm) & 376 & $36.0 \pm 14.25$ & 39.6 \\
\hline Calcium (gm) & 376 & $311.9 \pm 221.9$ & 71.2 \\
\hline Iron (mg) & 376 & $13.60 \pm 6.24$ & 45.9 \\
\hline Vitamin $\mathrm{A}(\mu \mathrm{g})$ & 376 & $200.1 \pm 194.4$ & 97.2 \\
\hline Thiamin (mg) & 376 & $0.48 \pm 0.26$ & 54.2 \\
\hline Riboflavin (mg) & 376 & $0.53 \pm 0.31$ & 58.5 \\
\hline Niacin $(\mathrm{mg})$ & 376 & $7.74 \pm 3.23$ & 41.7 \\
\hline Vitamin C (mg) & 375 & $33.0 \pm 31.46$ & 95.4 \\
\hline
\end{tabular}
a. All measurements are presented in $\mathrm{cm}$ except where indicated.
b. $\mathrm{mm}$.
c. $\mathrm{kg}$.
d. $w \mathrm{t}(\mathrm{kg}) / \mathrm{ht}^{2}(\mathrm{~m})$.
C.V. = coefficient of variation.

WB, and BCF appeared to be less variable, while the rest of the variables exhibit high anthropometric and nutritional variability.

In this study, variation between the sexes of each caste group was examined by comparison of means through the $t$ test. Table 5 presents the $t$ values for 23 anthropometric phenotypes of males and females of six caste groups. Height is not significantly different between sexes in Brahmin, Reddy, and Telaga castes, while it is significantly different in Nagara, Akshatriya, and Mala castes. Among the 
ڤิ)

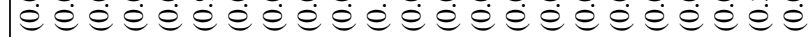
क m

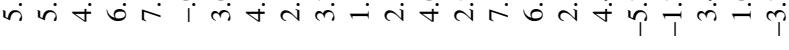

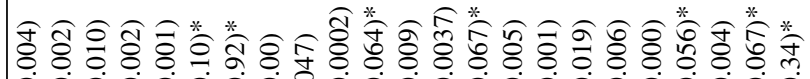

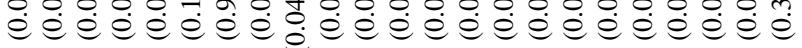

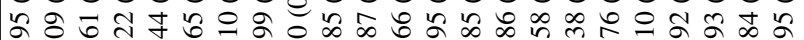
i

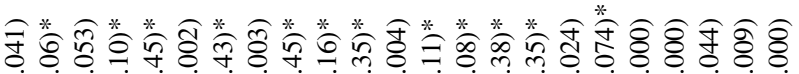

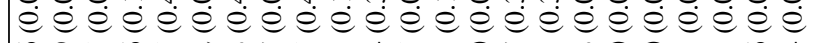
๖

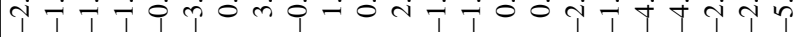

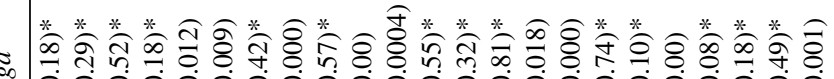

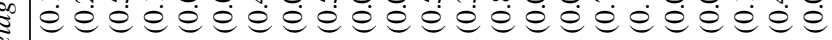
$m \&$ t $m$ n - $-\dot{0}-\mathrm{i}$ i

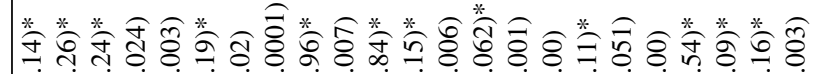

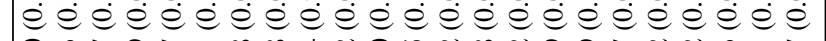

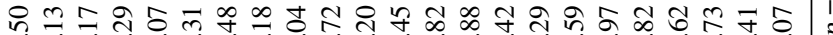

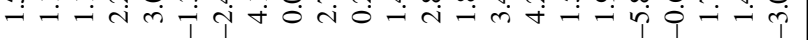

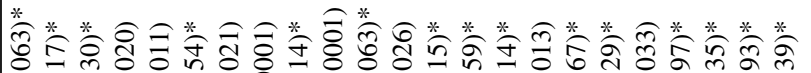

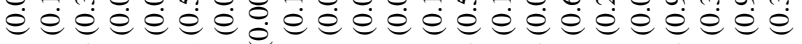

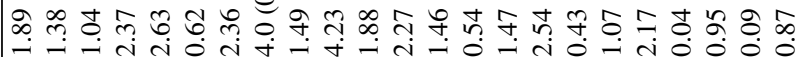

$\sum_{0}^{0}$

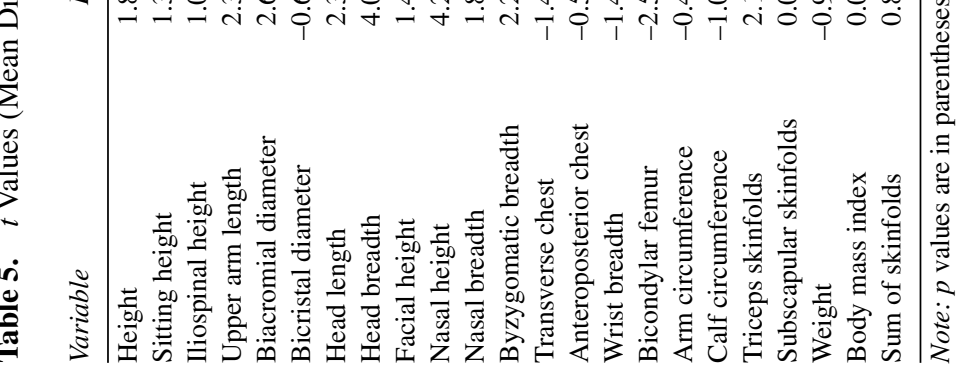


Brahmins, ARL, BAD, HL, HB, NH, BZB, BCF, and TRS were significant ( $p<$ 0.05). In the Reddy caste, variables such as ARL, BAD, HL, HB, NH, WB, BCF, CAC, TRS, and SSK were significant $(p<0.05)$, while TRC, APC, and WT were significant at $p<0.10$. In the Telaga caste, differences between males and females were significant $(p<0.05)$ for variables such as BAD, BID, HB, NH, NB, WB, $\mathrm{BCF}, \mathrm{CAC}$, and TRS. Among Nagaras, male and female differences were significant for HT, BID, HB, BZB, ARC, TRS, SSS, BMI, and SSK, while SHT, APC, and WT were significant at $p<0.10$. For Akshatriya and Mala castes, male and female differences were not significant at $p=0.05$ for a few variables such as BID, HL, NB, WT, BMI, and SSK.

Table 6 presents the heritability estimates $\left(h^{2}\right)$ and their associated standard errors for 23 anthropometric traits of the main data set. Also reported in these tables are the significant covariates $(p<0.10)$ of a given phenotype. Heritabilities for 23 anthropometric phenotypes were significant $(p<0.05)$ and varied from $25 \%$ (BMI) to 61\% (BZB), after accounting for the effects of phenotype-specific significant covariates. Among the covariates, age was the significant covariate for

Table 6. Estimates of Heritability Associated with Standard Errors and Significant Covariates

\begin{tabular}{lccl} 
Phenotype $^{a}$ & $n$ & $h^{2} \pm$ S.E. & Significant Covariates \\
\hline Height & 1909 & $0.358 \pm 0.047$ & sex, age, ng, ak \\
Sitting height & 1910 & $0.430 \pm 0.179$ & sex, age \\
Iliospinal height & 1910 & $0.319 \pm 0.050$ & sex, age, ng, ak \\
Upper arm length & 1909 & $0.268 \pm 0.049$ & sex, age, ng, ak \\
Biacromial diameter & 1906 & $0.440 \pm 0.047$ & sex, age \\
Transverse chest & 1903 & $0.268 \pm 0.051$ & sex, age, rd, tg, ak \\
Anteroposterior chest & 1903 & $0.402 \pm 0.068$ & age \\
Bicristal diameter & 1903 & $0.385 \pm 0.047$ & age \\
Head length & 1916 & $0.413 \pm 0.051$ & sex, age, rd, tg \\
Head breadth & 1909 & $0.447 \pm 0.051$ & sex, age, br, rd, tg, ng \\
Facial height & 1910 & $0.414 \pm 0.053$ & sex, age \\
Nasal height & 1910 & $0.417 \pm 0.051$ & age, br, ng \\
Nasal breadth & 1910 & $0.498 \pm 0.049$ & sex, age, tg, ak \\
Bizygomatic breadth & 1900 & $0.605 \pm 0.045$ & sex, age, rd, tg \\
Wrist breadth & 1916 & $0.330 \pm 0.048$ & sex, age, rd, tg, ng \\
Bicondylar femur & 1907 & $0.329 \pm 0.055$ & sex, age, br, rd, ng \\
Arm circumference & 1908 & $0.301 \pm 0.046$ & age \\
Calf circumference & 1917 & $0.400 \pm 0.045$ & sex, age, br, ng, ak \\
Triceps skinfolds & 1747 & $0.334 \pm 0.052$ & sex, age, br, ng, ak \\
Subscapular skinfolds & 1786 & $0.257 \pm 0.053$ & sex, age, rd, ak \\
Weight* & 1908 & $0.314 \pm 0.045$ & sex, age, br, ng, ak \\
Body mass index & 1903 & $0.250 \pm 0.047$ & sex, age, br \\
Sum of skinfolds & 1710 & $0.312 \pm 0.057$ & sex, age, rd, ng, ak \\
\hline
\end{tabular}

a. All heritabilities are significant at $p<0.001$ except where indicated; $* p<0.05$.

Note: Dummy variables are derived from original group variables; Mala $=$ reference caste; $\mathrm{ng}=\mathrm{Na}-$ gara; $\mathrm{ak}=$ Akshatriya; $\mathrm{tg}=$ Telaga; $\mathrm{rd}=$ Reddy; $\mathrm{br}=$ Brahmin . 


\section{6 / ARYA ET AL.}

all the traits, while sex and caste were not significant for four traits. Most of the traits exhibited moderate $h^{2}(30 \%-40 \%)$. Particularly, craniofacial measures showed higher $h^{2}(41 \%-61 \%)$ than the linear $(27 \%-43 \%)$ and other measures $(25 \%-44 \%)$. Caste effects were significant for $74 \%$ variables used in this study.

Heritability estimates with associated standard errors for the subset data with significant age, sex, caste, socioeconomic, and nutritional covariates are presented in Table 7. Heritabilities were obtained after accounting for the significant covariate effects. Nasal breadth, bizygomatic breadth, wrist breadth, and bicondylar femur showed higher heritabilities (52\%-72\%). Stature, biacromial diameter, facial height, calf circumference, body mass index, sum of skinfolds, sitting height, iliospinal height, biacromial diameter, nasal height, arm circumference, and triceps and subscapular skinfolds exhibited moderate heritabilities $(32 \%-42 \%)$. By contrast, upper arm length, transverse chest, bicristal diameter, head breadth, and weight yielded lower heritabilities (21\%-29\%). Age differences were significant for all traits, while sex differences were not signifi-

Table 7. Estimates of Heritability with Associated Standard Errors for the Subset with Significant Socioeconomic and Nutritional Covariates

\begin{tabular}{lccl} 
Phenotype & $n$ & $h^{2} \pm$ S.E. & \multicolumn{1}{c}{ Significant Covariates* } \\
\hline Height & 371 & $0.421 \pm 0.137$ & sex, age, rd, tg, ses, nia \\
Sitting height & 375 & $0.347 \pm 0.130$ & age \\
Iliospinal height & 371 & $0.356 \pm 0.161$ & br, rd, tg, age, pci, iro, ene, ribo, nia \\
Upper arm length & 373 & $0.262 \pm 0.051$ & sex, tg, ng, age, ene, iro, ribo \\
Biacromial diameter & 372 & $0.388 \pm 0.168$ & ak, age, vita \\
Transverse chest & 367 & $0.290 \pm 0.237$ & tg, ak, age, cal, vita, thia, nia \\
Anteroposterior chest & 371 & $0.332 \pm 0.249$ & sex, rd, tg, age, pro, cal, iro, nia \\
Bicristal diameter & 371 & $0.249 \pm 0.191$ & rd, tg, age, ses, pci, pro, cal, \\
Head length & 373 & $0.322 \pm 0.152$ & sex, rd, age, ses, pci \\
Head breadth & 369 & $0.212 \pm 0.161$ & age, cal, thia, rib, nia \\
Facial height & 372 & $0.480 \pm 0.201$ & br, tg, age, ene, pro \\
Nasal height & 369 & $0.336 \pm 0.165$ & br, tg, ak, age, ses, cal, vita, rib \\
Nasal breadth & 368 & $0.721 \pm 0.184$ & sex, br, rd, ak, age, ses, pci, pro, iro, thia \\
Bizygomatic breadth & 365 & $0.619 \pm 0.147$ & sex, age, pci, iro \\
Wrist breadth & 376 & $0.519 \pm 0.134$ & sex, rd, tg, age, iro, ribo \\
Bicondylar femur & 373 & $0.521 \pm 0.150$ & sex, rd, tg, age, vitc \\
Arm circumference & 372 & $0.300 \pm 0.171$ & sex, rd, age, pro, cal, thia, nia \\
Calf circumference & 375 & $0.449 \pm 0.251$ & sex, age, cal \\
Triceps skinfolds & 309 & $0.342 \pm 0.222$ & sex, age, br, ng, ak, pci, ene, pro, cal, thia, rib, nia \\
Subscapular skinfolds & 330 & $0.295 \pm 0.277$ & sex, br, age, pci, thia, ribo \\
Weight & 375 & $0.271 \pm 0.186$ & ak, age, thia, nia \\
Body mass index & 373 & $0.423 \pm 0.212$ & age \\
Sum of skinfolds & 301 & $0.443 \pm 0.239$ & sex, br, tg, ng, age, pci, pro, cal, rib, nia \\
\hline
\end{tabular}

Note: Abbreviations are as in Table 4; *significant at $p<0.10$; ses $=$ socioeconomic status, pci $=$ per capita income, pro $=$ protein, ene $=$ energy, iro $=$ iron, $c a l=$ calcium, vitc $=$ vitamin $\mathrm{C}$, vita $=$ vitamin $\mathrm{A}, \mathrm{rib}=$ riboflavin, nia $=$ niacin, thia $=$ thiamine. Mala $=$ reference caste, $\mathrm{ng}=$ Nagara $;$ ak $=$ Akshatriya; $\operatorname{tg}=$ Telaga; $r d=$ Reddy; $b r=$ Brahmin. Dummy variables are derived from original group variables. 
cant for 12 traits. Nutritional and caste effects were significant for most of the traits, while socioeconomic differences were significant for a few traits (Table 7).

Table 8 presents caste-specific heritability estimates of anthropometric phenotypes with associated standard errors for six caste groups. These analyses include age and sex as covariates. Among Brahmins, heritabilities for 15 traits were significant at $p<0.05$ and for 4 traits (SHT, BAD, CAC, WT) at $p<0.10$, while heritabilities for TRC, APC, BID, and BCF were found to be not significant. Among Reddies, heritabilities for SHT and NH were not significant, while the rest of the traits exhibited significant $(p<0.05)$ heritabilities. In contrast, heritabilities for all the traits were significant $(p<0.05)$ among Telagas. Among Nagaras, heritabilities for all traits were significant at $p=0.05$ except ARL, WB, and $\mathrm{BCF}$, which were significant at $p<0.01$. Among Akshatriyas, APC, BID, CAC, SSS, and SSK were not significant at $p=0.05$, but all of them were significant at $p<0.10$ except APC, which was not significant. All 23 traits were significant ( $p$ $<0.05$ ) among Malas. Overall, Telaga, Nagara, and Mala castes exhibited significant within-group differences. In all three analyses, craniofacial measures exhibited higher heritabilities compared to linear and soft tissue measures.

\section{Discussion}

Anthropometric phenotypes of Indian caste populations are of particular interest for quantifying the heritable portion of phenotypic variability, since genetic and environmental factors (or their interactions) including subtle socioeconomic and dietary differences across the caste groups affect variation in these phenotypes. Therefore, India has a great potential for the study of quantitative genetic variation within and between caste populations. In this study, as expected, age and sex differences were significant for the majority of the traits indicating the sexual dimorphism. Nutritional and caste effects were significant for most of the traits, while socioeconomic differences were significant for a few traits. Estimation of heritabilities through the variance components approach yielded a wide range of heritabilities (25\%-61\%) for 23 anthropometric phenotypes, and most of them were significant. Overall, most of these anthropometric phenotypes exhibited moderate $(30 \%-40 \%)$ heritabilities, while some of these heritability estimates were relatively low compared to those in other studies in the literature (Devi and Reddy 1983; Poosha et al. 1984; Byard et al. 1985b).

In the total sample, among the covariates, age was significant for all the traits, while sex and caste were not significant for four traits. Caste effects were significant for 17 phenotypes in comparison to the reference caste group. However, it is surprising that craniofacial measures $(41 \%-61 \%)$ showed higher heritabilities $\left(h^{2}\right)$ than the linear $(27 \%-43 \%)$ and other body fat measures $(25 \%-$ $44 \%)$. Specifically, these heritability patterns contradict the observation made by Osborne and DeGeorge (1959) that the longitudinal measurements tend to have higher familial correlations, thus implying higher heritabilities than do breadth or soft tissue measures. In fact, the observed higher heritabilities for craniofacial 


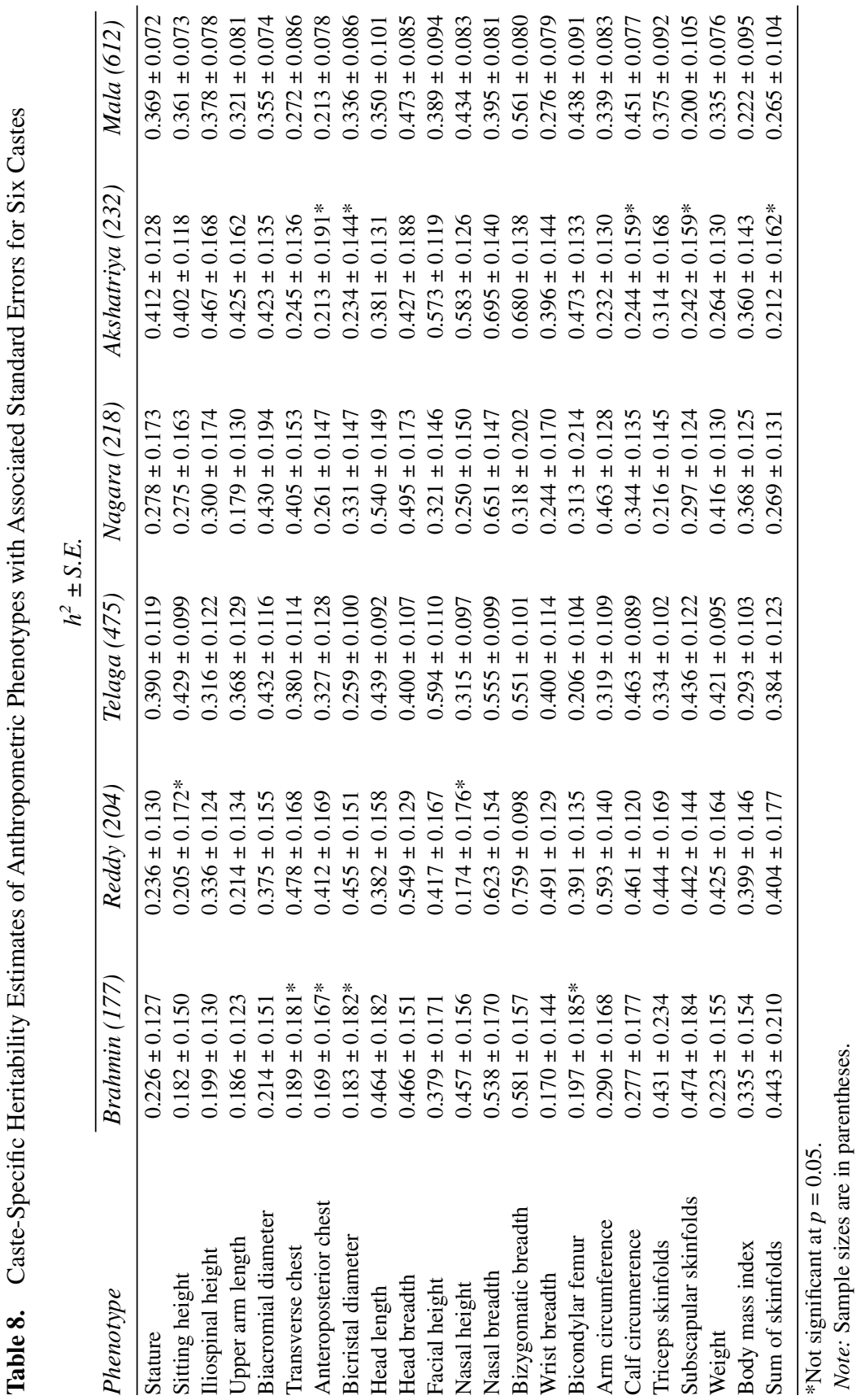


traits in the present study support the view that head and facial morphology is largely genetically determined in caste groups, since these differences may be due to differences in mandibular development (Poosha et al. 1984; Sharma and Susanne 1991). Remarkable effects of diverse environments on the phenotypic variance of craniofacial traits may indicate that selection pressures are operating on craniofacial traits, especially facial and mandibular traits (Sharma and Susanne 1991). For example, culturally associated selection pressures such as chewing habits, food types, and food preparation methods may exert significant effect on dentition including occlusion (Corruccini 1984; Sharma and Susanne 1991). However, the general trend in the heritability patterns observed in this study is in agreement with the findings of Nakata et al. (1974), Susanne (1975), and Devor et al. (1986a, 1986b), who found similar observations that bony measures have higher heritabilities than soft tissue measures among different human populations.

Heritabilities obtained from the subset data $(21 \%-72 \%)$ with significant socioeconomic and nutritional covariates were slightly higher for soft tissue measures compared to those from the main data set (25\%-61\%), thus indicating the effects of nutritional and socioeconomic covariates on soft tissue measures. In contrast, heritabilities were lower for linear and craniofacial traits with the exception of ST, WB, BF, and NB. In the subset data, however, traits that are more influenced by nutritional and socioeconomic factors have yielded higher heritabilities after accounting for their (covariate) effects. This pattern attests to the common notion that socioeconomic factors affect anthropometric phenotypes through nutritional factors and the incidence and severity of infections (Martorell and Habicht 1986; Tanner 1990), the most important proximate causes that influence the anthropometric phenotypes of the populations. Particularly, nutrient (macronutrients such as energy and protein, and micronutrients such as vitamin $\mathrm{A}$, thiamin, riboflavin, niacin, vitamin $\mathrm{C}$, calcium, and iron) intake exerts an influence indirectly on anthropometric phenotypes of human populations (Martorell and Habicht 1986; Gershoff et al. 1988). Therefore, it is important to identify the effects of nutrient intake in the populations under study, since several of the families across the caste groups are identified as having low standards of living and since dietary habits, in general, are caste-specific.

In these caste populations, as reported by Busi et al. (1987), the energy intake of preadolescent children in slum areas is much lower than recommended dietary allowance (RDA 1981; Gopalan et al. 1987), whereas the protein intake is more than RDA in areas that are not slums. Protein intake is higher in upper castes and higher income groups than the recommended allowances (Busi et al. 1987). Among adolescents the deficit in energy intake is 50\% less than the RDA in all the caste groups as well as in socioeconomic groups (Busi et al. 1987, 1988). Protein intakes are adequate in nonslum areas (low-polluted regions), while inadequate protein intakes are observed in the other areas. Protein consumption patterns of middle socioeconomic groups correspond well with the RDAs, while higher-income groups exceeded the RDA. In contrast, lower-in- 
come groups had lower protein intake while all other groups are low in energy (Busi et al. 1988). Thus, the observed slightly lower heritabilities for some traits in the larger sample compared to the subset sample may be attributable to the differential nutritional intake of a large number of families with poor qualitative and quantitative dietary habits.

Socioeconomic factors, that is, the children's environment strictly in terms of cultural and economic differentials in society, exert their influence through several pathways, such as nutrient intake and infection, on anthropometric phenotypes (Martorell and Habicht 1986). Moreover, life-style factors, including infant feeding and health practices and environmental sanitation, are also determined by the socioeconomic status of the family (Busi et al. 1987). Thus, in addition to age and sex differences, nutritional and caste effects were significant for most of the traits, while socioeconomic differences other than caste were significant for a few traits. Therefore, in the presence of greater diversity in the environments in terms of nutritional and socioeconomic factors, the estimated heritabilities would tend to be lower (Sharma 1987; Khoury et al. 1993).

Since castes are distinct entities, it is also important to determine the castespecific heritabilities for all the anthropometric phenotypes to examine the extent to which the morphological differences among the castes reflect underlying genetic variation. In this study, caste-specific heritabilities were also significant for most of the traits. In fact, using the main data set that included information from six caste groups (Table 6), a 5-degrees-of-freedom test for heterogeneity of the trait-specific $h^{2}$ estimate was performed. About $61 \%$ of the traits (ARL, TRC, HB, FHT, NH, NB, BZD, WB, BID, BCF, ARC, CAC, SSS, and SSK) used in the study showed evidence of heterogeneity $(p<0.05)$ for the trait-specific $h^{2}$ estimate among the caste groups. This finding is not surprising since we previously showed that both linear and craniofacial $\left(F_{S T} \pm\right.$ S.E. $\left.=0.027 \pm 0.002\right)$ and girth, breadth, and body fat $\left(F_{S T} \pm\right.$ S.E. $\left.=0.043 \pm 0.003\right)$ measures exhibited significant among-group variation (Arya 1999). These observations are consistent with our present finding that caste effects were significant for most of the variables used in this study (Table 6).

Given that several of the anthropometric traits are under strong genetic control in this study, it is appropriate to compare these heritabilities with genetically similar populations in order to understand the heritability patterns of these anthropometric phenotypes. Because of the paucity of data, it is not possible to compare heritabilities of all the traits of these caste groups with other studies from same-caste groups. However, heritability estimates of some of the traits of Akshatriya are compared to a genetically similar Jalari caste, an economically poor and undernourished fishing caste in Visakhapatnam (Devi and Reddy 1983), and most of the heritabilities are found to be comparable except that heritabilities for soft tissue measures of Kshatriya are slightly lower compared to those of Jalari families (Devi and Reddy 1983). This may be attributable to the differences in nutritional (i.e., undernutrition) and life-style factors besides the methodological differences. Since the heritability is a function of the trait, of the population, 
and of the environmental factors, it should be kept in mind that the heritability estimate for a given trait is specific to a given population (Feldman and Lewontin 1975; Sussane 1977; Falconer 1989). And, since additive genetic effects and environmental causes of variation differ among these caste populations, heritability estimate of a particular trait must be considered to refer to a particular caste population under particular conditions.

\section{Conclusions}

All heritabilities of anthropometric phenotypes were significant in these caste populations. The 23 anthropometric phenotypes considered in the complete data exhibited low to high heritabilities. Although heritabilities for some phenotypes were relatively low compared to the studies in the literature, they are in agreement with the general observation that the longitudinal and/or craniofacial measures tend to have higher familial correlations, thus implying higher heritabilities $\left(h^{2}\right)$ than the soft tissue measures. Thus, the observation that linear and craniofacial measures are more highly heritable than soft tissue measures is further verified in these caste populations. However, in this study, linear measures exhibited lower heritabilities compared to craniofacial measures. Overall, variability in heritabilities of anthropometric phenotypes of caste populations could be due to the effects of a number of environmental factors, such as low socioeconomic status, poor nutrient intake, malnutrition, and infections, on linear measures rather than craniofacial measures. However, the subset data with nutritional and socioeconomic factors as covariates fail to be in agreement with the pattern that craniofacial traits are more heritable than linear and soft tissue measures as indicated by the complete data. This may be due to the small sample size of the subset data or sampling error. Heritabilities obtained from the subset data, however, were slightly higher for most of the traits compared to the complete data set. Given that the caste groups are associated with distinct dietary and socioeconomic conditions, the heritabilities obtained from the subset data appear to be more precise, since nutritional and socioeconomic variables were included as covariates.

Since caste effects were significant for most of the phenotypes in comparison to the reference caste group, it is suggestive that intercaste differences among these castes are more prominent. However, the heritabilities are different in their magnitudes across the caste groups. According to the caste-specific analysis, the observed lower heritabilities for some traits in these caste populations may be attributable to the low standard of living of a majority of the subjects, leading to poor nutrition (i.e., undernutrition and/or malnutrition) besides low power due to smaller caste-specific sample sizes. In conclusion, craniofacial measures such as bizygomatic breadth, nasal breadth, and head breadth showed higher $h^{2}$ followed by longitudinal measurements such as stature, sitting height with moderate $h^{2}$, and soft tissue measures such as weight, skinfolds, and circumferences with low $h^{2}$ values. Thus, heritability patterns of anthropometric phenotypes observed in this study exhibited significant anthropometric variation among Andhra caste 


\section{2 / ARYA ET AL.}

populations. The relatively low heritabilities in these caste populations are largely attributable to extreme environmental effects. We are planning to use information on genetics of anthropometric traits obtained from this study to reconstruct the population structure of these caste populations.

Acknowledgments This research was supported in part by the department of environment (D.O.En.), Government of India. We thank the subjects for their participation and cooperation. We also thank G.M. Jyothi (Junior Research Fellow) for her help in the data collection.

Received 26 January 2001; revision received 9 November 2001.

\section{Literature Cited}

Almasy, L., and J. Blangero. 1998. Multipoint quantitative-trait linkage analysis in general pedigrees. Am. J. Hum. Genet. 62:1198-1211.

Amos, C.I. 1994. Robust variance components approach for assessing genetic linkage in pedigrees. Am. J. Hum. Genet. 54:535-543.

Arya, R. 1999. Genetic and environmental determinants of anthropometric phenotypes in caste populations of Visakhapatnam, India. Ph.D. diss., The University of Kansas, Lawrence, KS.

Balakrishnan, V. 1987. Basic elements in the population of the Indian sub-continent. Bull. Hum. Genet. 12:9-11.

Blangero, J. 1990. Population structure analysis using polygenic traits: Estimation of migration matrices. Hum. Biol. 62:27-48.

Busi, B.R., S. Modem, R. Arya et al. 1987. Food, dietary intake and feeding practices in urban slums of Visakhapatnam. Ind. J. Nutr. Dietet. 24:163-169.

Busi, B.R., S. Modem, R. Arya et al. 1988. Nutritional status of children in Visakhapatnam. In Modern Trends in Anthropology, A.N. Sharma, ed. New Delhi, India: Northern Book Center, 185193.

Busi, B.R., S. Modem, R. Arya et al. 1989. Nutrition and growth of certain population groups of Visakhapatnam. Visakhapatnam, India: Department of Anthropology, Andhra University.

Busi, B.R., S. Modem, R. Arya et al. 1991. Growth pattern among preschool children in urban slums of Visakhapatnam. Ind. J. Diet. Nutr. 28:188-193.

Byard, P.J., D.V.R. Poosha, and M. Satyanarayana. 1985a. Genetic and environmental determinants of height and weight in families from Andhra Pradesh, India. Hum. Biol. 57:621-633.

Byard, P.J., D.V.R. Poosha, M. Satyanarayana et al. 1985b. Path analysis of family resemblance for cranio-facial traits in Andhra Pradesh nuclear families and twins. Ann. Hum. Biol. 12(4):305314.

Byard, P.J., K. Sharma, J.M. Russell et al. 1984. A family study of anthropometric traits in a Punjab community: II. An investigation of familial transmission. Am. J. Phys. Anthropol. 64:97-104.

Chakraborthy, R. 1990. Quantitative traits in relation to population structure: Why and how are they used and what do they imply? Hum. Biol. 62:147-162.

Char, K.S.N., P. Lakshmi, K.B. Gopalan et al. 1989. Genetic differentiation among some endogamous populations of Andhra Pradesh, India. Am. J. Phys. Anthropol. 78:421-429.

Corrucini, R.S. 1984. An epidemiologic transition in dental occlusion in world populations. Am. J. Orthodon. 86:419-426. 
Devi, M.R., and G.G. Reddy. 1983. Heritability of body measurements among the Jalari population in Visakhapatnam. Ann. Hum. Biol. 10:483-485.

Devor, E.J., M. McGue, M.H. Crawford et al. 1986a. Transmissible and nontransmissible components of anthropometric variation in the Alexanderwohl Mennonites: I. Description and familial correlations. Am. J. Phys. Anthropol. 69:71-82.

Devor, E.J., M. McGue, M.H. Crawford et al. 1986b. Transmissible and nontransmissible components of anthropometric variation in the Alexanderwohl Mennonites: II. Resolution by path analysis. Am. J. Phys. Anthropol. 69:83-92.

Duggirala, R., and M.H. Crawford. 1994. Human population structure: Use of quantitative characters. In Human Genetics: New Perspectives, P.K. Seth and S. Seth, eds. New Delhi: Omega Scientific Publishers, 35-62.

Dwyer, J.T. 1991. Concept of nutritional status and its measurement. In Anthropometric Assessment of Nutritional Status, J.H. Himes, ed. New York, NY: Wiley-Liss, Inc. 5-28.

Eveleth, P.B. 1986. Population differences in growth. In Human Growth: A Comprehensive Treatise. F. Falkner and J. M. Tanner, eds. New York, NY: Plenum Press, 221-239.

Eveleth, P.B., and J.M. Tanner. 1990. World-wide Variation in Human Growth. Cambridge, UK: Cambridge University Press.

Falconer, D.S. 1989. Introduction to Quantitative Genetics. London, UK: Longman Scientific \& Technical.

Feldman, M.W., and R.C. Lewontin. 1975. The heritability hang-up. Science 190:1163-1168.

Gershoff, S.N., R.B. McGandy, A. Nondasut et al. 1988. Nutrition studies in Thailand: Effects of calories, nutrient supplements, and health intervention on growth of preschool Thai village children. Am. J. Clin. Nutr. 48:1214-1218.

Gopalan, C., B.V.R. Sastry, and S.C. Balasubramanyam. 1987. Nutritive Value of Indian foods. Hyderabad: National Institute of Nutrition (Indian Council of Medical Research).

Harrison, G.A., and L.H. Schmitt. 1989. Variability in stature growth. Ann. Hum. Biol. 16:45-51.

Hopper, J.L., and J.D. Mathews. 1982. Extensions to multivariate normal models for pedigree analysis. Ann. Hum. Genet. 46:373-383.

Jelliffe D.B., and E.F.P. Jelliffe 1989. Community Nutritional Assessment. New ed. New York, NY: Oxford University Press.

Kaur, D.P., and R. Singh. 1981. Parent-adult offspring correlations and heritability of body measurements in a rural Indian population. Ann. Hum. Biol. 8:333-339.

Khoury, M.J., T.H. Beaty, and B.H. Cohen. 1993. Fundamentals of Genetic Epidemiology. Oxford, UK: Oxford University Press.

Kumar, A., and A.K. Jain. 1988. The growth pattern of sitting height, skull and chest circumference in Varanasi school children of upper socioeconomic group. Ind. J. Pediat. 55:591-598.

Lamb, B.T. 1975. India: A World in Transition. New York, NY: Prager Publishers.

Lange, K., and M. Boehnke. 1983. Extensions to pedigree analysis. IV. Covariance components models for multivariate traits. Am. J. Med. Genet. 14:513-524.

Majumder P.P., B.U. Shankar, A. Basu et al. 1990. Anthropometric variation in India: A statistical appraisal. Curr. Anthropol. 31:94-103.

Malhotra, K.C. 1978. Morphological composition of people of India. J. Hum. Evol. 7:45-63.

Malhotra, K.C. 1984. Population structure among the Dhangar caste-cluster of Maharashtra, India. In The People of South Asia, J.R. Lukacs, ed. New York, NY: Plenum Press, 295-323.

Malik, P., and R. Singh. 1991. Effect of genetic and environmental factors on body measurements of first, second, and third degree relatives. J. Hum. Biol. 2:45-51.

Martorell, R., and J-P. Habicht. 1986. Growth in early childhood in developing countries. In Human Growth: A Comprehensive Treatise, Vol. 3., F. Falkner and J. M. Tanner, eds. New York, NY: Plenum Press, 241-259.

Minitab. 1994. Minitab Reference Manual, Release 10, Minitab Inc.

Mueller, W.H., and M. Titcomb. 1977. Genetic and environmental determinants of growth of schoolaged children in a rural Colombian population. Ann. Hum. Biol. 4:1-15. 


\section{4 / ARYA ET AL.}

Nakata, M., P.L. Yu, B. Davis et al. 1974. Genetic determinants of craniofacial morphology: A twin study. Ann. Hum. Genet. 37:431-443.

Osborne, R.H., and F.V. DeGeorge. 1959. Genetic Basis of Morphological Variation. Cambridge, MA: Harvard University Press.

Poosha, D.V.R., P.J. Byard, M. Satyanarayana et al. 1984. Family resemblance for craniofacial measurements in velanti Brahmins from Andhra Pradesh, India. Am. J. Phys. Anth. 65:15-22.

Reddy, B.N. 1998. Body mass index and its association with socioeconomic and behavioral variables among socioeconomically heterogeneous populations of Andhra Pradesh, India. Hum. Biol. 5:901-917.

Reddy, V., M. Shekar, P. Rao et al. 1992. Nutrition in India. NIN, I.C.M.R. Hyderabad, India.

Relethford, J.H., and F.C. Lees. 1982. The use of quantitative traits in the study of human population structure. Yrbk. Phys. Anthropol. 25:113-132.

Self, S.G., and K.Y. Liang. 1987. Asymptotic properties of maximum likelihood ratio tests and nonstandard conditions. J. Am. Stat. Assoc. 82:605-610.

Sharma, A., and G. Talukder. 1987. Environment and genetic polymorphisms in Indian populations: An overview. Bull. Hum. Genet. 12:3-8.

Sharma, K. 1987. Genetic variance estimates and familial resemblance for body size traits. Acta Genet. Med. Gemellol. 36:549-555.

Sharma, K., P.J. Byard, J.M. Russel et al. 1984. A family study of anthropometric traits in a Punjabi community: I. Introduction and familial correlations. Am. J. Phys. Anthropol. 63:389-395.

Sharma, K., and C. Susanne. 1991. Comparative genetic variance and heritability of head and facial traits in northwest Indian and Belgian twins. Am. J. Hum. Biol. 3:315-324.

Singh, K.S. 1993. People of India: The profile of national project (1985-92). Curr. Sci. 64:10.

Singh, I.P., and M.K. Bhasin. 1968. Anthropometry. Delhi, India: Kamla-Raj Enterprises.

Sokal, R.R., and F.J. Rohlf. 1981. Biometry. San Francisco, CA: W.H. Freeman and Company.

Susanne, C. 1975. Genetic and environmental influences on morphological characteristics. Ann. Hum. Biol. 2:279-287.

Susanne, C. 1977. Heritability of anthropological characters. Hum. Biol. 49:573-580.

Tanner, J.M. 1990. Fetus into Man. Cambridge, MA: Harvard University Press.

Weiner, J.S., and J.A. Lourie. 1981. Practical Human Biology. London, UK: Academic Press. 